\title{
Inhibitory effects of evodiamine on human osteosarcoma cell proliferation and apoptosis
}

\author{
XIAODONG BAI, HAI MENG, LIFENG MA and AI GUO
}

Department of Orthopedics, Beijing Friendship Hospital, Capital Medical University, Xicheng, Beijing 100050, P.R. China

Received June 15, 2014; Accepted November 6, 2014

DOI: $10.3892 / 01.2014 .2791$

\begin{abstract}
Osteosarcoma is a primary malignancy of bone, which is characterized by the proliferation of malignant mesenchymal cells, particularly in children and adolescents. Evodiamine is extracted from a variety of traditional Chinese medicines, which has been reported to induce apoptosis in certain tumors, including cervical, prostate and breast cancer, however, its effect on oestosarcoma cells remains unclear. The aim of the present study was to investigate the effect of evodiamine on osteosarcoma cell proliferation and apoptosis, and explore the associated underlying molecular mechanism. A Cell Counting Kit 8 assay was performed to detect the effects of evodiamine on the proliferation of human osteosarcoma U2OS cells. Annexin V-fluorescein isothiocyanate/propidium iodide staining was performed to analyze the apoptotic rate of the cells. The effect of evodiamine on the protein expression levels of B-cell lymphoma-2 (Bcl-2), Bcl-2-associated $\mathrm{X}$ protein (Bax), caspase-3 and survivin were detected by performing western blot analysis. Evodiamine inhibited the growth of human osteosarcoma U2OS cells by inhibiting cell proliferation and inducing cell apoptosis. Western blotting demonstrated that evodiamine downregulated the expression of Bcl-2, caspase-3 and survivin, and upregulated the expression of Bax in human osteosarcoma cells. Evodiamine effectively inhibited proliferation and induced apoptosis of osteosarcoma cells in a dose-dependent manner via downregulation of Bcl-2, caspase-3 and survivin protein expression levels and upregulation of Bax protein expression levels.
\end{abstract}

\section{Introduction}

Osteosarcoma is the most commonly diagnosed primary malignancy of bone, particularly among children and adolescents $(1,2)$. It is characterized by the proliferation of malignant

Correspondence to: Dr Ai Guo, Department of Orthopedics, Beijing Friendship Hospital, Capital Medical University, 95 Yong'an Road, Xicheng, Beijing 100050, P.R. China

E-mail: aiguo4ty@163.com

Key words: evodiamine, osteosarcoma cells, proliferation, apoptosis mesenchymal cells that are capable of producing osteoid or immature bone (3), and is associated with high morbidity, early metastasis and mortality (4-6). Survival of osteosarcoma is poor despite the aggressive use of surgery, chemotherapy, and/or radiotherapy (7). Furthermore, surgery cannot halt the metastasis of the tumor and chemotherapy is restricted by the development of resistance and various side effects. Currently, traditional Chinese medicine (TCM) is commonly administered to cancer patients as an adjunct to conventional therapies to improve the quality of life by alleviating symptoms and side effects (8). The active gradients of TCM have been demonstrated to inhibit tumor cell proliferation and induce tumor cell apoptosis $(9,10)$.

Evodiamine is a natural alkaloid compound extracted from a variety of TCMs, such as Evodia rutaecarpa (Juss.) Benth., E. rutaecarpa (Juss.) Benth. var. officinalis (Dode) Huang and E. rutaecarpa (Juss.) Benth. var. bodinieri (Dode) Huang. Vasodilatation (11), anti-inflammation (12), analgesia (13) and anti-tumor (14) effects are the major efficacies of evodiamine. Additionally, evodiamine has been shown to induce the apoptosis of various tumors, such as cervical (15), prostatic $(16,17)$ and breast cancer $(18)$, as well as melanoma (19) and leukemia (20), via the inhibition of proliferation, blockade of the cell cycle, induction of apoptosis and suppression of metastasis. However, to the best of our knowledge, no studies been conducted that focus on the effects of evodiamine in osteosarcoma.

In the present study, human osteosarcoma U2OS cells were cultured with different concentrations of evodiamine to explore its effect on U2OS cell proliferation and apoptosis. Additionally, the expression levels of apoptosis-associated proteins were determined to understand the underlying mechanism.

\section{Materials and methods}

Reagents. Evodiamine was purchased from the National Institutes for Food and Drug Control (Beijing, China), and dimethyl sulfoxide, RPMI-1640 medium and fetal bovine serum (FBS) were purchased for cell culture from Gibco-BRL (Carlsbad, CA, USA). An annexin V-fluorescein isothiocyanate/propidium iodide (FITC/PI) kit was purchased from Sigma-Aldrich (St. Louis, MO, USA) for cell apoptosis detection, and a Cell Counting Kit $8(\mathrm{CCK}-8)$ was purchased from Beyotime Institute of Biotechnology (Haimen, China) 
for the cell viability assay. Furthermore, for western blot analysis, monoclonal mouse anti-human B-cell lymphoma (Bcl-2; 1:1,000; cat. no. sc-130307) and polyclonal mouse anti-human Bcl-2-associated X protein (Bax; 1:1,000; cat. no. sc-20067) antibodies, and polyclonal peroxidase-conjugated goat anti-mouse (1:1,000; cat. no. sc-2354) antibodies were purchased from Santa Cruz Biotechnology, Inc. (Dallas, TX, USA). Monoclonal mouse-anti-human caspase-3 (1:1,000; cat. no. 9668), mouse anti-human $\beta$-actin (1:1,000; cat. no. 3700) and mouse anti-human survivin (1:1,000; cat. no. 2802) antibodies were purchased from Cell Signaling Technology (Danvers, MA, USA). The luminol-enhanced chemiluminescence kit was obtained from GE Healthcare (Chalfont, UK).

Cell line and culture conditions. Human osteosarcoma U2OS cells were purchased from the Cell Bank of the Chinese Academy of Sciences (Shanghai, China) and grown in RPMI-1640 medium with 10\% (v/v) FBS, $100 \mathrm{U} / \mathrm{ml}$ streptomycin and $100 \mathrm{U} / \mathrm{ml}$ penicillin. The cell cultures were maintained in a $37^{\circ} \mathrm{C}$ incubator with a humidified atmosphere of $5 \% \mathrm{CO}_{2}$. U2OS cells were harvested in the logarithmic growth phase and used in following experiments.

CCK- 8 assay. The viability of the U2OS cells was assessed using a CCK- 8 assay. The U2OS cells $\left(1 \times 10^{4} / \mathrm{ml}\right)$ were plated on a 96-well plate at $100 \mu 1 /$ well and incubated overnight. A total of 24 wells containing cultured cells of the 96-well plate were then divided into four groups ( $\mathrm{n}=6$ wells in each group): control group [treated with $0.1 \%$ DMSO $(\mathrm{v} / \mathrm{v})$ ] and three evodiamine groups (treated with $0.5,2.5$ and $12.5 \mu \mathrm{g} / \mathrm{ml}$, respectively). After culturing with and without evodiamine for $48 \mathrm{~h}, 10 \mu \mathrm{l}$ CCK- 8 solution was added to each well, according to the manufacturer's instructions. After $2 \mathrm{~h}$ incubation at $37^{\circ} \mathrm{C}$, the optical density value was measured at a wavelength of $450 \mathrm{~nm}$. The following formula was used to calculate the cell survival rate: Cell survival rate $(\%)=1-\{[$ (control well) - (evodiamine well)] / (control well)\} x 100\%.

Annexin V-FITC/PI flow cytometry analysis. U2OS cells $\left(1 \times 10^{6} / \mathrm{ml}\right)$ were plated on a 96-well plate at $2,000 \mu \mathrm{l} /$ well and incubated overnight. A total of 24 wells containing cultured cells of the 96-well plate were then divided into four groups ( $\mathrm{n}=6$ wells in each group): control group [treated with $0.1 \%$ DMSO $(\mathrm{v} / \mathrm{v})]$ and three evodiamine groups (treated with 0.5 , 2.5 and $12.5 \mu \mathrm{g} / \mathrm{ml}$, respectively). After culturing with and without evodiamine for $48 \mathrm{~h}$, the cells were harvested, and the percentages of apoptotic or necrotic cells were determined using the Annexin V-FITC/PI Apoptosis Detection kit, according to the manufacturer's instructions, in a flow cytometer (FACSCalibur ${ }^{\mathrm{TM}}$; BD Biosciences, Franklin Lakes, NJ, USA).

Western blot analysis. The expression levels of cellular proteins were evaluated by performing western blot analysis. U2OS cells $\left(1 \times 10^{6} / \mathrm{ml}\right)$ were plated on a 96-well plate at $2,000 \mu \mathrm{l} /$ well and incubated overnight. A total of 24 wells containing cultured cells of the 96-well plate were then divided into four groups ( $\mathrm{n}=6$ wells in each group): control group [treated with $0.1 \%$ DMSO $(\mathrm{v} / \mathrm{v})]$ and three evodiamine groups (treated with 0.5 , 2.5 and $12.5 \mu \mathrm{g} / \mathrm{ml}$, respectively). Following treatment for $12 \mathrm{~h}$,

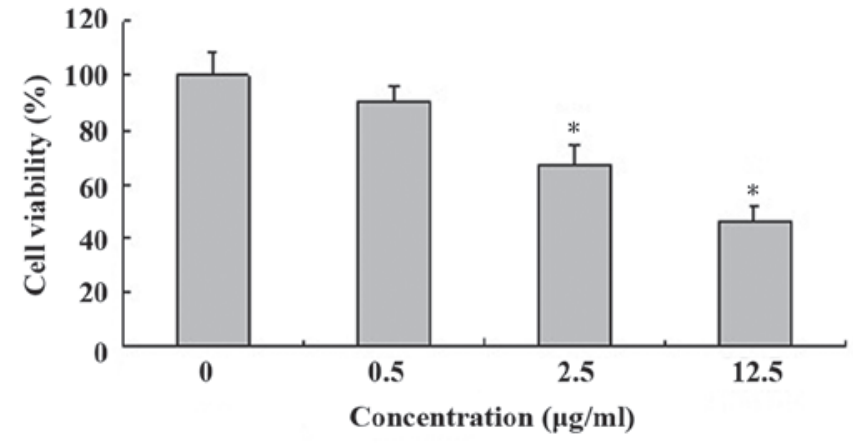

Figure 1. Proliferative inhibition effects of evodiamine on human osteosarcoma U2OS cells ( ${ }^{*} \mathrm{P}<0.05$, vs. the control group).

total proteins were extracted and the protein concentrations were determined using a bicinchoninic acid protein assay. Equal amounts of protein from each sample were separated by $12 \%$ SDS-PAGE. Following electrophoresis, the proteins were electroblotted onto polyvinylidene difluoride membranes for $1 \mathrm{~h}$ at room temperature. Subsequently, the membranes were individually incubated with the following primary antibodies (dilution, 1:1,000) overnight at $4^{\circ} \mathrm{C}$ : Mouse anti-human Bcl-2 monoclonal antibody, mouse anti-human Bax polyclonal antibody, mouse anti-human caspase-3 and survivin monoclonal antibody. The membranes were washed three times and incubated with the secondary peroxidase-conjugated antibody (dilution, 1:1,000) for $1 \mathrm{~h}$ at room temperature. Following incubation, the membranes were washed and the peroxidase activity was visualized on X-ray film using the luminol-enhanced chemiluminescence kit (GE Healthcare), according to the manufacturer's instructions. $\beta$-actin was used as a reference for normalization. The protein bands were quantified using ImageJ software (http://rsb.info.nih.gov/ij/) (National Institutes of Health, Bethesda, MD, USA).

Statistical analysis. The data are expressed as the mean \pm standard deviation. Statistical correlation of data was checked for significance by analysis of variance and Student's t-test. $\mathrm{P}<0.05$ was considered to indicate a statistically significant difference. These analyses were performed using SPSS software (version 11; SPSS, Inc., Chicago, IL, USA).

\section{Results}

Evodiamine suppresses proliferation in human osteosarcoma U2OS cells. CCK-8 assays were performed to detect the impact of evodiamine on the proliferation of U2OS cells. The U2OS cell line was incubated with $0,0.5,2.5$ and $12.5 \mu \mathrm{g} / \mathrm{ml}$ evodiamine. After $48 \mathrm{~h}$ incubation, the U2OS cells treated with 0.5 , 2.5 and $12.5 \mu \mathrm{g} / \mathrm{ml}$ evodiamine exhibited reduced levels of cell viability, to $89.90 \pm 6.12,66.65 \pm 8.01$ and $46.22 \pm 6.23 \%$, respectively, compared with the control group (Fig. 1). These results indicated that evodiamine treatment induced cell growth inhibition in a concentration-dependent manner in the U2OS human osteosarcoma cell line. The cells treated with $2.5(\mathrm{P}<0.05)$ and $12.5 \mu \mathrm{g} / \mathrm{ml}(\mathrm{P}<0.05)$ evodiamine exhibited a statistically significant reduced level of cell viability compared with the control group. 
A

(F2)[Ungated] 0-dilmd.LMD : FL1 LOG/FL3 LOG

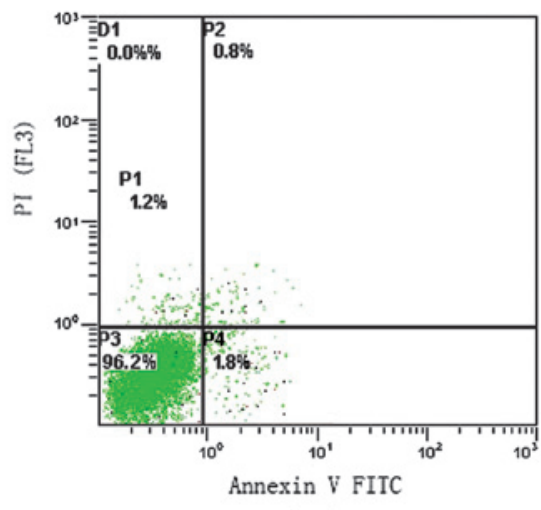

(FL1)

C

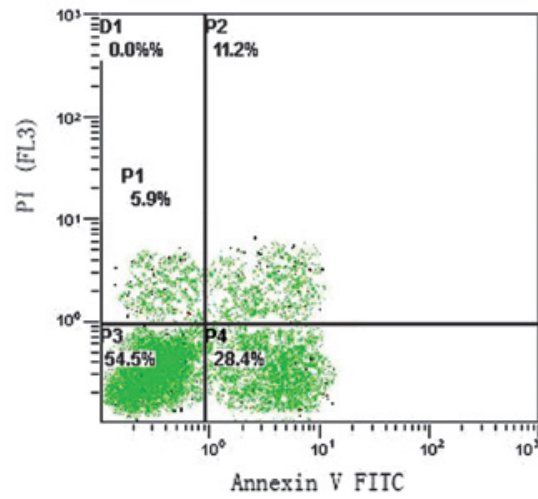

(FL1)
B (F2)(Ungated] 0-di md.LMO : FL1 LOG/FL3 LOG

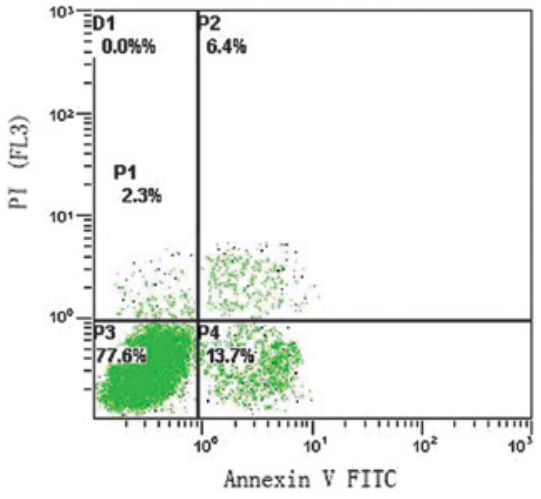

(FL1)

D

(F2)]Ungated] 0-dilmd.LMD : FL1 LOG/FLI LOG

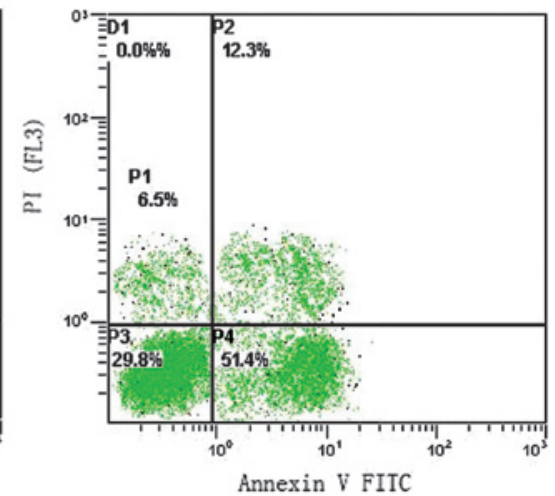

(FL1)

Figure 2. Effect of evodiamine on the apoptosis of U2OS cells using flow cytometry. (A) Control group; (B) $0.5 \mu \mathrm{g} / \mathrm{ml}$ evodiamine; (C) $2.5 \mu \mathrm{g} / \mathrm{ml}$ evodiamine; and (D) $12.5 \mu \mathrm{g} / \mathrm{ml}$ evodiamine.

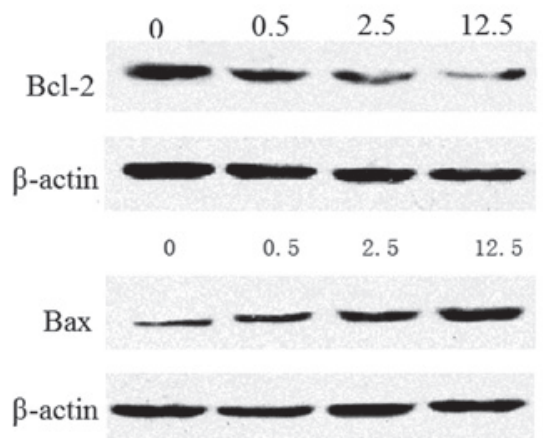

Figure 3. Protein expression levels of Bcl-2 and Bax following treatment with increasing concentrations of evodiamine for $12 \mathrm{~h} .0$, control group; $0.5,0.5 \mu \mathrm{g} / \mathrm{ml}$ evodiamine; $2.5,2.5 \mu \mathrm{g} / \mathrm{ml}$ evodiamine; $12.5,12.5 \mu \mathrm{g} / \mathrm{ml}$ evodiamine.

Evodiamine induces apoptosis in human osteosarcoma U2OS cells. U2OS cells were incubated with $0,0.5,2.5$ and $12.5 \mu \mathrm{g} / \mathrm{ml}$ evodiamine for $48 \mathrm{~h}$ and were analyzed by flow cytometry. The proportions of early apoptotic cells were determined as 1.8, 13.7, 28.4 and 51.4\%, respectively (Fig. 2). These results indicated that evodiamine treatment induced cell apoptosis in a concentration-dependent manner in the U2OS human osteosarcoma cell line.

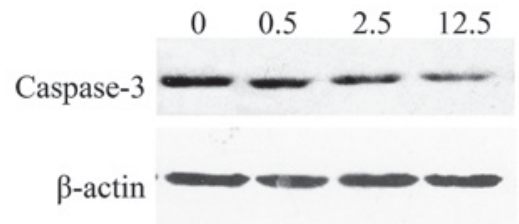

Figure 4. Protein expression levels of caspase-3 following treatment with increasing concentrations of evodiamine for $12 \mathrm{~h} .0$, control group; $0.5,0.5 \mu \mathrm{g} / \mathrm{ml}$ evodiamine; $2.5,2.5 \mu \mathrm{g} / \mathrm{ml}$ evodiamine; $12.5,12.5 \mu \mathrm{g} / \mathrm{ml}$ evodiamine.

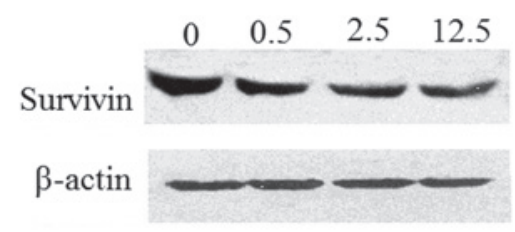

Figure 5. Protein expression levels of survivin following treatment with increasing concentrations of evodiamine for $12 \mathrm{~h} .0$, control group; $0.5,0.5 \mu \mathrm{g} / \mathrm{ml}$ evodiamine; $2.5,2.5 \mu \mathrm{g} / \mathrm{ml}$ evodiamine; $12.5,12.5 \mu \mathrm{g} / \mathrm{ml}$ evodiamine.

Effect of evodiamine on the expression levels of Bcl-2 and Bax protein. To determine the molecular mechanism by which evodiamine induces the apoptosis of U2OS cells, the protein 
expression levels of Bcl-2 (an inhibitor of apoptosis) (21) and Bax (a pro-apoptotic member of the Bcl-2 family) (22) were assessed by performing western blot analysis. As indicated in Fig. 3, quantitative analysis revealed that the protein expression levels of $\mathrm{Bcl}-2$ significantly decreased $(\mathrm{P}<0.05)$ and the protein expression levels of Bax significantly increased $(\mathrm{P}<0.05)$ following treatment with evodiamine for $12 \mathrm{~h}$, compared with the control group. Therefore, evodiamine may induce apoptosis of U2OS cells through the mitochondrial pathway.

Evodiamine decreases the expression levels of caspase-3 in U2OS cells. The expression levels of caspase-3 (a pro-apoptotic protein) was downregulated in a concentration-dependent manner as the concentration of evodiamine increased (Fig.4). The results indicated that the apoptosis induced by evodiamine may involve the caspase cascade.

Evodiamine decreases the expression levels of survivin in U2OS cells. Survivin, an anti-apoptotic protein, exerts an important role in the development of tumors. The expression levels of survivin were downregulated in a concentration-dependent manner as the concentration of evodiamine was increased (Fig.5). The results indicated that survivin may be a target of the apoptosis pathway induced by evodiamine.

\section{Discussion}

Previous studies have demonstrated the apoptosis-inducing and chemotherapy resistance-reversing effects of TCMs and their active ingredients (8-10). Evodiamine is one of the main constituents of Evodiae fructus, and exhibits antitumor and antiproliferative properties $(16,23)$. In the present study, experimental data demonstrated that evodiamine significantly inhibits the proliferation and induces the apoptosis of U2OS cells in a dose-dependent manner. Following $48 \mathrm{~h}$ co-culturing with $12.5 \mu \mathrm{g} / \mathrm{ml}$ evodiamine, the cell viability was reduced to $46.22 \pm 6.23 \%$ and the proportion of early apoptotic cells was $51.4 \%$, which indicates that evodiamine may efficiently inhibit the proliferation of U2OS cells. Tumorigenesis is closely associated with the loss of control of cell proliferation and diminished apoptosis, thus, evodiamine administration may exert a curative effect on osteosarcoma patients.

Programmed cell death, or apoptosis, is important for the development and homeostasis of the majority of tissue types (24). Apoptosis is regulated by various factors and signaling pathways, such as the endoplasmic reticulum pathway, the mitochondrial pathway and the death ligand pathway (25). The mitochondrial pathway is activated in response to the activation of the anti-apoptotic protein Bcl-2 and the pro-apoptotic protein Bax of the Bcl-2 family, which promote the secretion of cytochrome $c$ (24) and activate caspase-3 and -9 in the downstream signaling pathways of Bcl-2 and Bax (26-28). However, Bcl-2 indirectly inhibits caspase-3 activation in a variety of pro-apoptotic conditions (29). Bcl-2 may prevent the accumulation of cytochrome $c$, subsequently preserving capase- 3 in the inactive zymogen state, which leads to the inhibition of the apoptotic cascade (30). A previous study demonstrated that reduced $\mathrm{Bcl}-2$ expression levels caused by evodiamine administration resulted in increased mitochondrial cytochrome $c$ release, and an increased ratio of Bax/Bcl-2 expression was closely associated with evodiamine-induced apoptosis (14). Survivin, an anti-apoptotic protein, may facilitate apoptosis-resistance in specific cells, and is an important target in current antitumor research (31-32). Survivin specifically binds to members of the caspase family of proteins and inhibits the activity of caspase- 3 to block apoptosis. Furthermore, survivin expression is positively associated with the expression levels of Bcl-2, showing a synergistic effect, and is negatively associated with the expression levels of Bax, demonstrating an antagonistic effect (33-36).

Western blot analysis was performed to detect the expression levels of apoptosis-associated proteins Bcl-2, Bax, caspase-3 and survivin, and it was identified that the ratio of $\mathrm{Bax} / \mathrm{Bcl}-2$ increased with increasing concentrations of evodiamine. The differential expression of caspase-3 verified that evodiamine may induce apoptosis of U2OS tumor cells via the mitochondrial pathway. In addition, survivin is an independent index of osteosarcoma prognosis $(31,37,38)$; in the present study, the expression levels of survivin decreased with increasing concentrations of evodiamine. Thus, survivin served as a target for the regulation of evodiamine-induced apoptosis in osteosarcoma, and was associated with Bcl-2, Bax and caspase- 3 expression levels.

In conclusion, the present study identified that the mitochondrial pathway and induced survivin expression may be mechanisms by which evodiamine inhibits proliferation and induces apoptosis in osteosarcoma cells. Therefore, evodiamine may be used as an adjuvant agent to chemotherapeutics in the treatment of osteosarcoma. However, additional studies are required to explore the toxicity of evodiamine in vivo, as well as its tolerance and pharmacokinetic characteristics.

\section{References}

1. Mirabello L, Troisi RJ and Savage SA: Osteosarcoma incidence and survival rates from 1973 to 2004: data from the Surveillance, Epidemiology, and End Results Program. Cancer 115: 1531-1543, 2009.

2. Osaki M, Takeshita F, Sugimoto Y, et al: MicroRNA-143 regulates human osteosarcoma metastasis by regulating matrix metalloprotease-13 expression. Mol Ther 19: 1123-1130, 2011.

3. Federman N, Bernthal N, Eilber FC and Tap WD: The multidisciplinary management of osteosarcoma. Curr Treat Option Oncol 10: 82-93, 2009.

4. Salah S, Ahmad R, Sultan I, et al: Osteosarcoma with metastasis at initial diagnosis: Current outcomes and prognostic factors in the context of a comprehensive cancer center. Mol Clin Oncol 2: 811-816, 2014.

5. Qu JT, Wang M, He HL, Tang Y and Ye XJ: The prognostic value of elevated vascular endothelial growth factor in patients with osteosarcoma: a meta-analysis and systemic review. J Cancer Res Clin Oncol 138: 819-825, 2012.

6. Nagarajan R, Kamruzzaman A, Ness KK, et al: Twenty years of follow-up of survivors of childhood osteosarcoma: a report from the Childhood Cancer Survivor Study. Cancer 117: 625-634, 2011.

7. Ta HT, Dass CR, Choong PF and Dunstan DE: Osteosarcoma treatment: state of the art. Cancer Metastasis Rev 28: 247-263, 2009.

8. Jia L, Ma S, Hou X, et al: The synergistic effects of traditional Chinese herbs and radiotherapy for cancer treatment. Oncol Lett 5: 1439-1447, 2013.

9. Shi RX, Ong CN and Shen HM: Luteolin sensitizes tumor necrosis factor- $\alpha$-induced apoptosis in human tumor cells. Oncogene 23: 7712-7721, 2004.

10. Lin SY, Liu JD, Chang HC, et al: Magnolol suppresses proliferation of cultured human colon and liver cancer cells by inhibiting DNA synthesis and activating apoptosis. J Cell Biochem 84: 532-544, 2002. 
11. Chiou WF, Chou CJ, Shum AY and Chen CF: The vasorelaxant effect of evodiamine in rat isolated mesenteric arteries: mode of action. Eur J Pharmacol 215: 277-283, 1992.

12. Choi YH, Shin EM, Kim YS, Cai XF, Lee JJ and Kim HP: Anti-inflammatory principles from the fruits of Evodia rutaecarpa and their cellular action mechanisms. Arch Pharm Res 29: 293-297, 2006.

13. Kobayashi Y: The nociceptive and anti-nociceptive effects of evodiamine from fruits of Evodia rutaecarpa in mice. Planta Med 69: 425-428, 2003.

14. Fei XF, Wang BX, Li TJ, et al: Evodiamine, a constituent of Evodiae Fructus, induces anti-proliferating effects in tumor cells. Cancer Sci 94: 92-98, 2003.

15. Zhang $\mathrm{Y}, \mathrm{Wu}$ LJ, Tashiro S, Onodera $\mathrm{S}$ and Ikejima $\mathrm{T}$ : Evodiamine induces tumor cell death through different pathways: apoptosis and necrosis. Acta Pharmacol Sin 25: 83-89, 2004

16. Kan SF, Yu CH, Pu HF, Hsu JM, Chen MJ and Wang PS: Anti-proliferative effects of evodiamine on human prostate cancer cell lines DU145 and PC3. J Cell Biochem 101: 44-56, 2007.

17. Kan SF, Huang WJ, Lin LC and Wang PS: Inhibitory effects of evodiamine on the growth of human prostate cancer cell line LNCaP. Int J Cancer 110: 641-651, 2004.

18. Liao CH, Pan SL, Guh JH, et al: Antitumor mechanism of evodiamine, a constituent from Chinese herb Evodiae fructus, in human multiple-drug resistant breast cancer NCI/ADR-RES cells in vitro and in vivo. Carcinogenesis 26: 968-975, 2005.

19. Zhang Y, Wu LJ, Tashiro S, Onodera S and Ikejima T: Evodiamine induces A375-S2 cell death through two different pathways. Yao Xue Xue Bao 38: 650-653, 2003 (In Chinese).

20. Huang YC, Guh JH and Teng CM: Induction of mitotic arrest and apoptosis by evodiamine in human leukemic T-lymphocytes. Life Sci 75: 35-49, 2004.

21. Hockenbery DM, Oltvai ZN, Yin XM, et al: Bcl-2 functions in an antioxidant pathway to prevent apoptosis. Cell 75: 241-251, 1993.

22. Antonsson B: Bax and other pro-apoptotic Bcl-2 family "killer-proteins" and their victim the mitochondrion. Cell Tissue Res 306: 347-361, 2001.

23. Jiang $\mathrm{J}$ and $\mathrm{Hu} \mathrm{C}$ : Evodiamine: a novel anti-cancer alkaloid from Evodia rutaecarpa. Molecules 14: 1852-1859, 2009.

24. Brunelle JK and Letai A: Control of mitochondrial apoptosis by the Bcl-2 family. J Cell Sci 122: 437-441, 2009.

25. Fiandalo MV and Kyprianou N: Caspase control: protagonists of cancer cell apoptosis. Exp Oncol 34: 165-175, 2012.
26. Yang J, Liu X, Bhalla K, et al: Prevention of apoptosis by Bcl-2: release of cytochrome c from mitochondria blocked. Science 275: 1129-1132, 1997.

27. Siu WP, Pun PB, Latchoumycandane C and Boelsterli UA: Bax-mediated mitochondrial outer membrane permeabilization (MOMP), distinct from the mitochondrial permeability transition, is a key mechanism in diclofenac-induced hepatocyte injury: Multiple protective roles of cyclosporin A. Toxicol Appl Pharmacol 227: 451-461, 2008.

28. Ohtsuka T, Buchsbaum D, Oliver P, Makhija S, Kimberly R and Zhou T: Synergistic induction of tumor cell apoptosis by death receptor antibody and chemotherapy agent through JNK/p38 and mitochondrial death pathway. Oncogene 22: 2034-2044, 2003.

29. Swanton E, Savory $\mathrm{P}$, Cosulich $\mathrm{S}$, et al: $\mathrm{Bcl}-2$ regulates a caspase-3/caspase-2 apoptotic cascade in cytosolic extracts. Oncogene 18: 1781-1787, 1999.

30. Park JW, Choi YJ, Suh SI, et al: Bcl-2 overexpression attenuates resveratrol-induced apoptosis in U937 cells by inhibition of caspase-3 activity. Carcinogenesis 22: 1633-1639, 2001.

31. Osaka E, Suzuki T, Osaka S, et al: Survivin expression levels as independent predictors of survival for osteosarcoma patients. J Orthop Res 25: 116-121, 2007.

32. Altieri DC: Survivin, versatile modulation of cell division and apoptosis in cancer. Oncogene 22: 8581-8589, 2003

33. Lu CD, Altieri DC and Tanigawa N: Expression of a novel antiapoptosis gene, survivin, correlated with tumor cell apoptosis and p53 accumulation in gastric carcinomas. Cancer Res 58: 1808-1812, 1998.

34. Tanaka K, Iwamoto S, Gon G, Nohara T, Iwamoto M and Tanigawa N: Expression of survivin and its relationship to loss of apoptosis in breast carcinomas. Clin Cancer Res 6: 127-134, 2000.

35. Kawasaki H, Altieri DC, Lu CD, Toyoda M, Tenjo T and Tanigawa N: Inhibition of apoptosis by survivin predicts shorter survival rates in colorectal cancer. Cancer Res 58: 5071-5074, 1998.

36. Tamm I, Wang Y, Sausville E, et al: IAP-family protein survivin inhibits caspase activity and apoptosis induced by Fas (CD95), Bax, caspases, and anticancer drugs. Cancer Res 58: 5315-5320, 1998.

37. Altieri DC: Survivin, cancer networks and pathway-directed drug discovery. Nat Rev Cancer 8: 61-70, 2008.

38. Suzuki A and Shiraki K: Tumor cell 'dead or alive': caspase and survivin regulate cell death, cell cycle and cell survival. Histol Histopathol 16: 583-593, 2001. 